\title{
Modeling in TRNSYS of a Single Effect Evaporation System Powered by a Rankine Cycle
}

\author{
S. Casimiro ${ }^{1,2}$, C. loakimidis ${ }^{3}$, J. Mendes $^{4}$, M. Giestas ${ }^{4}$ \\ ${ }^{1}$ MIT|Portugal Program, Sustainable Energy Systems, Lisbon, Portugal \\ ${ }^{2} \mathrm{IN}+$, Instituto Superior Técnico, Lisbon, Portugal \\ ${ }^{3}$ DeustoTech, Energy Unit, University of Deusto, Bilbao, Spain \\ ${ }^{4}$ Laboratório Nacional de Energia e Geologia, UESEO, Lisbon, Portugal
}

\begin{abstract}
The paper presents an analysis of a Single Effect Evaporation (SEE) system as a pre-study to the feasibility of concentrated solar power plants (CSP) powering desalination units for cogeneration of water and electricity. An algorithm to model a SEE system in steady-state operation was made and is described in this work. This algorithm was implemented in TRNSYS environment, and a simple analysis was conducted of a SEE system powered by a Rankine cycle used in CSP plants.
\end{abstract}

Keywords: Desalination, Single Effect Evaporation, TRNSYS, simulation.

\section{Introduction}

Water scarcity has been a problem for many regions around the world, even if only during some critical periods during the year. This has various economical, social and environmental impacts. Technological developments, the need for clean water, and the growing concerns about water supply availability in different areas of the world have justified investments in various types of desalination technologies powered by different energy sources. As desalination processes require intense energy consumption, energy security to power it and market fluctuations for fuel prices have made these important issues when deciding whether or not to install a specific type of desalination system in a particular place.

Typically, areas with high levels of solar radiation also suffer a high instance of drought. The combination of desalination and solar technologies in such areas can present an interesting investment, if these regions are near sources of water (i.e., ocean or other bodies of non-drinkable water). Solar technologies can be a reliable source of energy and can be partnered with desalination units in many such locations (DLR, 2007).

This work is a pre-study on the feasibility of the usage of CSP technologies to power Desalination units $(C S P+D)$, and in it, it is presented a study on the performance of a SEE system coupled with a Rankine cycle providing the necessary heat to power a desalination unit of this kind. The main part of this work consisted in modeling the SEE system. The Rankine cycle is not evaluated in detail.

The SEE system has a very low efficiency when compared with other desalination methods (Ettouney, 2002). The only reason why it was chosen for this study is because it forms the basis to understand more complex and efficient evaporation systems, such as the Multi Effect Desalination (MED) and the Multi Stage Flash (MSF). A simple technical evaluation of the usage of the SEE system is presented at the end of the work, along with a comparison of its performance with the other main desalination competing 
technologies (Blanco, 2011): Thermal Vapor Compression (TVC)-MED, Low Temperature (LT) - MED and Reverse Osmosis (RO).

For this, a transient systems simulation program with a modular structure called TRNSYS has been used. This program has been used as a reference in the solar community for many years, including for the simulation of CSP plants.

\section{SEE system}

The SEE system has very limited industrial applications. One of the measures for understanding the performance of a desalination system is the thermal performance ratio (PR) (also called Gain Output Ratio (GOR)), calculated by dividing the amount of distilled water produced by the mass of steam used (Ettouney, 2002). PR values for the SEE normally are just below one. The PR values for the more efficient evaporation technologies (LT-MED and TVC-MED namely) (Blanco, 2011), are roughly one order of magnitude higher, comparing with a SEE.

\section{Nomenclature:}

Areas:

Ae - Area of Evaporator, $\left[\mathrm{m}^{2}\right]$

Power:

Ac - Area of Condenser, $\left[\mathrm{m}^{2}\right]$

$\mathrm{Qe} \quad$ - Evaporator heat transfer rate, $[\mathrm{kJ} / \mathrm{s}]$

Qc - Condenser heat transfer rate, $[\mathrm{kJ} / \mathrm{s}]$

Constants:

Cp - Specific heat at constant pressure, $[\mathrm{kJ} / \mathrm{kg} \stackrel{\circ}{\circ} \mathrm{C}]$

Dimensionless:

PR - Performance Ratio (or Gained Output Ratio, GOR)

sMcw - Specific cooling water flow rate

Flow Rates:

Ms - Mass of steam, $[\mathrm{kg} / \mathrm{s}]$

Md - Mass of Distillate produced, [kg/s]

Mt - Total Mass (Mf+Mcw), $[\mathrm{kg} / \mathrm{s}]$

Mcw - Mass of cooling water, $[\mathrm{kg} / \mathrm{s}]$

$\mathrm{Mb}$ - Mass of brine, $[\mathrm{kg} / \mathrm{s}]$

Mf - Mass of feed seawater, $[\mathrm{kg} / \mathrm{s}]$

Mv - Mass of vapor formed in the condenser, $[\mathrm{kg} / \mathrm{s}]$

Temperatures:

Ts - Low Pressure Turbine steam temperature input, [ $\left.{ }^{\circ} \mathrm{C}\right]$

$\mathrm{Tb} \quad$ - Boiling temperature, $\left[{ }^{\circ} \mathrm{C}\right]$

Tv - Temperature of the formed Vapor in the condenser, $\left[{ }^{\circ} \mathrm{C}\right]$

Tf - Temperature of the feed seawater, $\left[{ }^{\circ} \mathrm{C}\right]$

Tcw - Temperature of the cooling water, $\left[{ }^{\circ} \mathrm{C}\right]$

BPE - Boiling point elevation, $\left[{ }^{\circ} \mathrm{C}\right]$

LMTDC - Logarithmic temperature difference, $\left[{ }^{\circ} \mathrm{C}\right]$

Salinity:

$\mathrm{Xf} \quad$ - Salinity of the feed seawater [weight \%]

$\mathrm{Xb} \quad$ - Salinity of the Brine [weight \%]

Latent Heat:

$\lambda s \quad$ - Latent heat of input steam, [kJ/kg]

$\lambda v \quad$ - Latent heat of vapor formed in the evaporator, $[\mathrm{kJ} / \mathrm{kg}]$

Heat Transfer Coefficient:

Ue - Evaporator heat transfer coefficient, [kJ/s m $\left.{ }^{2} \stackrel{\circ}{\circ}\right]$

Uc - Condenser heat transfer coefficient, $\left[\mathrm{kJ} / \mathrm{s} \mathrm{m}^{2} \stackrel{\circ}{\circ} \mathrm{C}\right]$ 


\subsection{Process description}

The main components of a SEE system are the evaporator and the condenser, as shown in Figure 1. Each of these blocks consists of an enclosed vapor space, evaporator/condenser heat exchange tubes, an un-evaporated water pool, a line for the removal of non-condensable gases, water distribution system, and a mist eliminator (Ettouney, 2002). In each of these "blocks", the two fluid systems are separated by the heat exchange tubes. Only energy is exchanged, and no mass transfers occur.

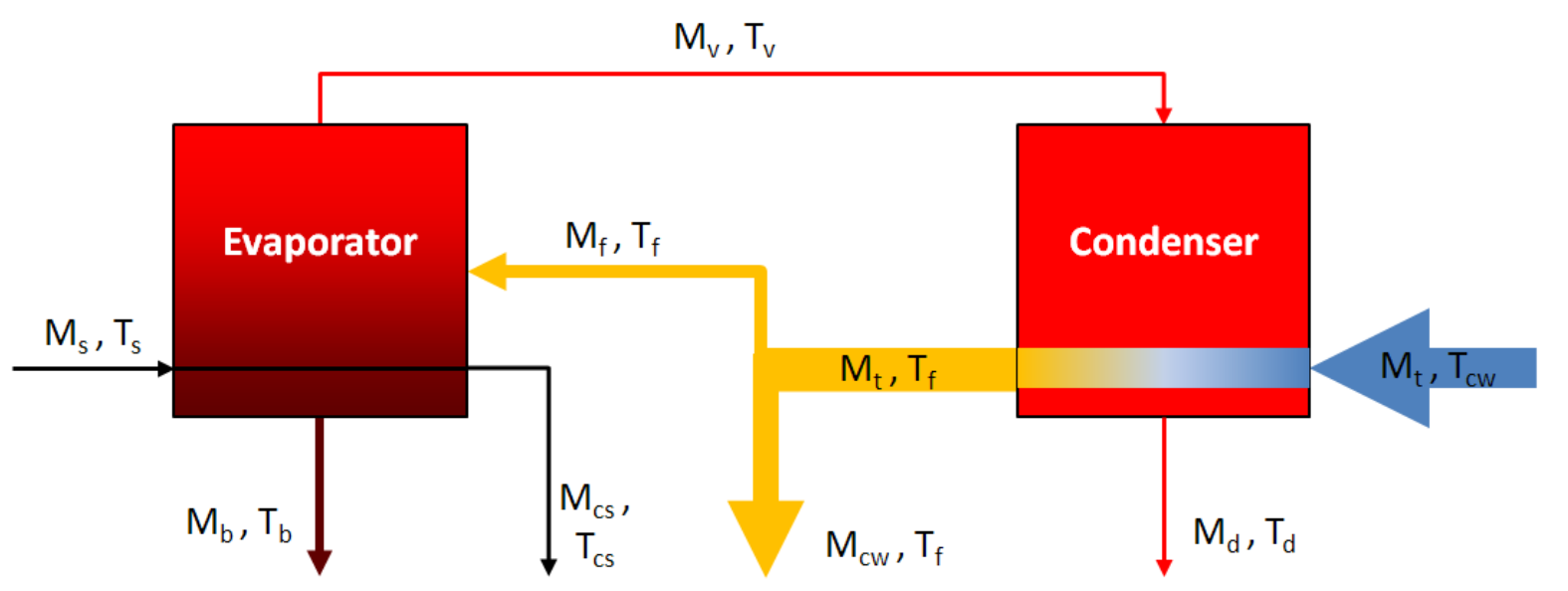

Figure 1 - Single Effect Desalination process

A mass of seawater (Mt) enters the condenser at seawater temperature (Tcw). Here this water gets preheated (Tf), due to the heat transfer $(\mathrm{Qe})$ that occurs when the mass of vapor coming from the Evaporator (Mv) is condensed. Not all of this preheated seawater is used to produce fresh water (Md), and only part of it enters the evaporator after flowing through the condenser. A large quantity of energy is wasted in this manner as most of the preheated water after leaving the condenser is discarded (Mcw). To condense the entire vapor coming from the evaporator, more cold seawater is needed than the one required to create it in the first place.

The part of the preheated seawater that enters the evaporator (Mf), receives an energy transfer from the evaporator's main heat source (Qe) (in this simulation, the steam from the Rankine cycle Low Pressure Turbine (LPT)). As the steam mass (Ms) coming from the LPT passes through the heat transfer tubes in the evaporator, it condenses, releasing its latent heat energy ( $\lambda \mathrm{s})$ to the preheated water mass (Mf) that came from the condenser. Assuming that the steam from the LPT is saturated (100\% vapor), after leaving the evaporator, it will exit at the same temperature (Tcs) that it entered (Ts), but will be $100 \%$ liquid. In reality steam outputs from LPT are not saturated, having a quality between 80 to $95 \%$, but for the purpose of this theoretical work it is assumed a quality of $100 \%$ for inlet vapor in the evaporator, and $0 \%$ for outlet.

Due to the energy transfer from the condensation of the LPT steam, the temperature of the preheated water increases in the evaporator, reaching its maximum temperature (the boiling temperature (Tb)). To avoid scaling problems, not all the preheated seawater entering the evaporated is vaporized. This would cause the system to lose its efficiency as the heat transfer coefficients (Ue and Uc) would start suffering and corrosion would seriously affect the materials. Because of this, part of the energy from the latent heat is used for sensible heat increase of the water entering the evaporator (up to the boiling temperature) and only the remaining is used to vaporize part of the evaporator's Mf. The preheated water which enters the 
evaporator that is not vaporized is discarded as brine $(\mathrm{Mb})$ back to the sea with a higher salt concentration $(\mathrm{Xb})$ than the seawater. Doing so leads to a big loss of energy as this water is warm.

The temperature of the vapor formed inside of the evaporator (Tv) is actually lower than the maximum temperature that the seawater reaches as liquid state inside the evaporator. This is due to the salt presence in seawater (Xf), causing the Boiling Point Elevation (BPE). The higher the concentration of salt in the water, the lower the partial pressure of water is, resulting in the BPE. Salt molecules reduce the total area of exposure of water molecules to the gaseous phase. The pressure that these water molecules can produce in the presence of salt molecules is therefore reduced and the boiling temperature of the solution is thus higher than if it was only pure water.

The vapor formed in the evaporator (Mv) is salt free. As it passes through the condenser, it releases its latent heat $(\lambda v)$ preheating the incoming seawater (Mt) and closing the loop. A big loss of energy also occurs at this point as the condensed distilled vapor (Md) leaves the system at a higher temperature than Tcw.

The loss of energy with the brine and distilled water outputs at high temperature, plus the usage of only part of the preheated water leaving the condenser justify the low performance ratio of the SEE system (Ettouney, 2002).

\subsection{Process Modeling under Steady-State operation}

The evaporator and condenser created in TRNSYS for this work represent a SEE system in its basic format, assuming a steady-state operation. The system can determine the equilibrium regarding operating temperatures and mass balances for every moment. As steady-state operation was considered, this SEE system ignores the values obtained in the previous time-step calculations as no thermal capacitance is considered. For example, if from one second to the other a significant increase in temperatures or mass occurs on the input, the simulation will not take into account the inertia of the system regarding these changes. The equilibrium that it will be calculated will thus not be valid.

It has been taken into account that desalination plants and power plants operate within a small range of temperatures and mass flows (apart from start-up and shut-down), and because of that it was decided that for this initial study it would be considered a steady-state operation (Ettouney, 2006), (Mataix, 2000). The steady-state formulation of the SEE process also means that the TRNSYS components would have lower degree of complexity and it would be possible to compare results obtained with the literature available (which for SEE systems the majority assumes steady-state formulations).

In the formulation of this SEE system, the aim was to make a system with the least amount of inputs possible, so that it would be more flexible, and calculations for equilibriums would require less information for a determined situation. To run it, the inputs needed are:

1. Seawater characteristics: $\mathrm{Xf}, \mathrm{Tcw}, \mathrm{Cp}$ (of water);

2. Heat transfer areas: Ae, Ac;

3. Maximum admissible salinity in the brine produced: $\mathrm{Xb}$;

4. Heat source characteristics powering the evaporator: Ts, Ms (assuming always saturated vapor)

Having these inputs, the system obtains the equilibrium in steady-state conditions for the operational temperatures and mass flow rates of water used and produced, being the most relevant: Mf, Md, Tv and Tf. The other outputs are: Mv, Mb, Tb, BPE, $\lambda s, \lambda v$, Qe, Ue, PR, Mt, Mcw, Qc, Uc, sMcw. 
Although $\mathrm{Xb}$ is a physical output of the SEE system, it was defined as an input when modeling for two reasons. Firstly, it would reduce the number of unknown variables, making the calculations less complex. Secondly, during the operation of a desalination plant, the brine has a negative impact in the ecosystems when discarded back to the sea. Operators of these plants will have to limit the maximum brine salinity they will accept a priori.

The equations considered to model the SEE system were (Ettouney, 2002):

Evaporator:

$Q e=M f \times C p \times(T b-T f)+M v \times \lambda v$

$Q e=A e \times U e \times T s-T b$

$X b \times M f-M v=M f \times X f$

Condenser:

$Q c=M t \times C p \times T f-T c w$

$Q c=A c \times U c \times(L M T D) c$

Auxiliary equations:

$$
\begin{aligned}
& M f=M d+M b \\
& Q e=M s \times \lambda s \\
& Q c=M v \times \lambda v \\
& \lambda s=A-(B \times T s)+\left(C \times T s^{2}\right)-\left(D \times T s^{3}\right) \\
& \lambda v=A-(B \times T v)+\left(C \times T v^{2}\right)-\left(D \times T v^{3}\right) \text {, where } \\
& A=2501.897149 ; B=-2.407064037 ; C=1.192217 \times 10^{-3} \\
& T v=T b-B P E \\
& B P E=E \times X b+F \times X b^{2}+G \times X b^{3} \text {, for the ranges }(1 \leq \mathrm{X} \leq 16 \%) \text { and }\left(10 \leq \mathrm{T} \leq 180^{\circ} \mathrm{C}\right) \\
& \mathrm{E}=\left(8.325 \times 10^{-2}\right)+\left(1.883 \times 10^{-4} \times \mathrm{Tb}\right)+\left(4.02 \times 10^{-6} \times \mathrm{Tb}^{2}\right) \\
& \mathrm{F}=\left(-7.625 \times 10^{-4}\right)+\left(9.02 \times 10^{-5} \mathrm{~Tb}\right)-\left(5.2 \times 10^{-7} \times \mathrm{Tb}^{2}\right) \\
& \mathrm{G}=\left(1.522 \times 10^{-4}\right)-\left(3 \times 10^{-6} \mathrm{~Tb}\right)-\left(3 \times 10^{-8} \times \mathrm{Tb}^{2}\right) \\
& U e=1.9695+1.2057 \times 10^{-2} \times \mathrm{Tb}-8.5989 \times 10^{-5} \times \mathrm{Tv}^{2}+\left(2.5651 \times 10^{-7} \mathrm{Tv}^{3}\right) \\
& U c=1.7194+3.2063 \times 10^{-3} \times \mathrm{Tv}+\left(1.5971 \times 10^{-5} \times \mathrm{Tv}^{2}\right)-\left(1.9918 \times 10^{-7} \mathrm{Tv}^{3}\right) \\
& \text { LMTD } c=\frac{(T f-T c w)}{\ln \frac{T v-T c w}{T v-T f}}
\end{aligned}
$$


The key to understanding how the equilibrium for the SEE system was obtained in this work is to know that only one possible value for Tf results in an equilibrium between the evaporator and the condenser (given the eight necessary inputs mentioned before). As Figure 2 shows (for a particular SEE system where only the Tf changes), increasing the Tf entering the evaporator increases Mv production. In opposite, the more Mv enters the condenser, the lower the resulting Tf will be (if more water has to pass through the condenser within the same amount of time, less energy will be absorbed per unit mass).

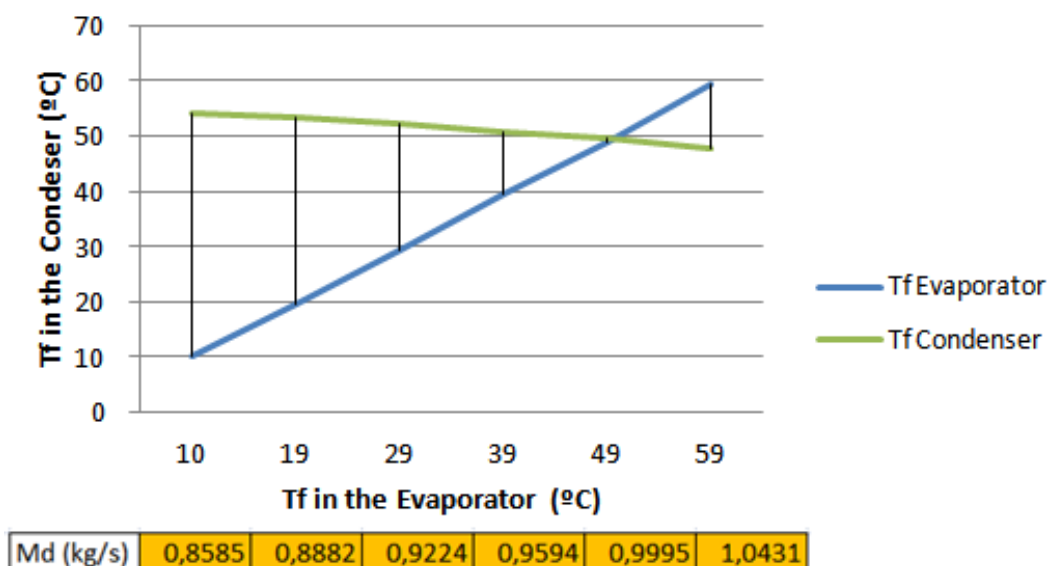

Figure 2 - Impact of Tf in the evaporator and condenser operation.

This means that only one value for $\mathrm{Tf}$ results in the correct amount of Mv produced to keep the system in steady-state operation through time (if all conditions allow an equilibrium to be reached in the first place). If a different value for $\mathrm{Tf}$ is used in the evaporator, a different amount of $\mathrm{Mv}$ will be produced. This will unbalance the Tf output leaving the condenser (that feeds the evaporator) making impossible a steadystate operation.

Using iterations it is possible to find the correct value for Tf since the maximum and minimum theoretical values for it are known. The maximum is $\mathrm{Ts}$, and the minimum is obtained by calculating the value of $\mathrm{Tf}$ when (LMTD)c tends to zero.

By defining $\mathrm{Xb}$ as an input, the calculation for the equilibrium will always set an Md corresponding to the maximum brine salinity. For the same Mf, the more Mv formed, the less Mb and higher Xb, as indicated by equation (3).

Although Mf is a physical inlet for the evaporator, it was defined as an output as was with $\mathrm{Xb}$, to reduce the complexity of the mathematical system to be solved and make it more flexible. In this case the flexibility was given by eliminating an input altogether instead of locking it (as it was done with $\mathrm{Xb}$ ).

In order to obtain valid results from simulations, the following boundaries were imposed to the system, and if any of these thresholds were surpassed, the simulation would assume that the SEE system would shut-down, and all outputs will be zero: 
Evaporator thresholds:

$$
\begin{gathered}
\mathrm{Tb}<10 \vee \mathrm{Tb}>180 \\
X b<1 \vee X b>16 \\
\mathrm{Xf}<1 \vee \mathrm{Xf}>16 \\
\mathrm{Xf}>\mathrm{Xb} \\
\mathrm{Tcw}>\mathrm{Ts} \\
\mathrm{Tcw} \leq 0 \\
\mathrm{Tf}>\mathrm{Ts} \\
\mathrm{Ms} \leq 0 \\
\mathrm{Ae} \leq 0
\end{gathered}
$$

Condenser thresholds:

$$
\begin{gathered}
\mathrm{Tf} \leq \mathrm{Tcw} \\
\mathrm{Mt}<M f \\
\mathrm{Mv}<0 \\
\mathrm{Tv} \leq \mathrm{Tcw} \\
\mathrm{Ac} \leq 0 \\
T c w \leq 0 \\
L M T D \quad c \leq 0
\end{gathered}
$$

\subsubsection{Solution Algorithm}

To calculate the equilibrium of mass flow rates and temperatures between the evaporator and condenser, the following steps were used (after setting the eight necessary inputs):

1. Using equation (1) $\mathrm{Tb}$ is calculated as it is the only unknown variable. This equation indicates the maximum temperature that the seawater can reach inside the evaporator, using this heat transfer area and heat source. The value of $\mathrm{Tb}$ is calculated keeping in mind that the maximum and minimum theoretical temperatures for $\mathrm{Tb}$ are: Ts and Tcw, respectively;

2. Equation (3) is used to replace Mf in equation (1). After this, equation (1) is left only with two unknown variables: Tf and Md.

3. Using equations (5) and equation (1) (modified in the last step), it is calculated by iteration which Tf in the evaporator will produce an Mv that will increase the Mt up to the same Tf when it will leave the condenser. For that a loop is used until an answer is found:

a. a value for Tf is given in the modified equation (1) and an Md is calculated.

b. in equation (5) the Tf and Mv (from point a. above) are used to see if the left side equals the right side. If yes, $\mathrm{Tf}$ is found. If not, the loop restarts from a) again with a different $\mathrm{Tf}$.

4. If a valid Tf is found, this value is used in equation (4) to find the total Mt. If no valid Tf is found, the SEE will consider all outputs as zero.

The connections between the evaporator and condenser in the SEE system are depicted in Figure 3, where all the inputs, outputs and parameters for these two components can be seen. 


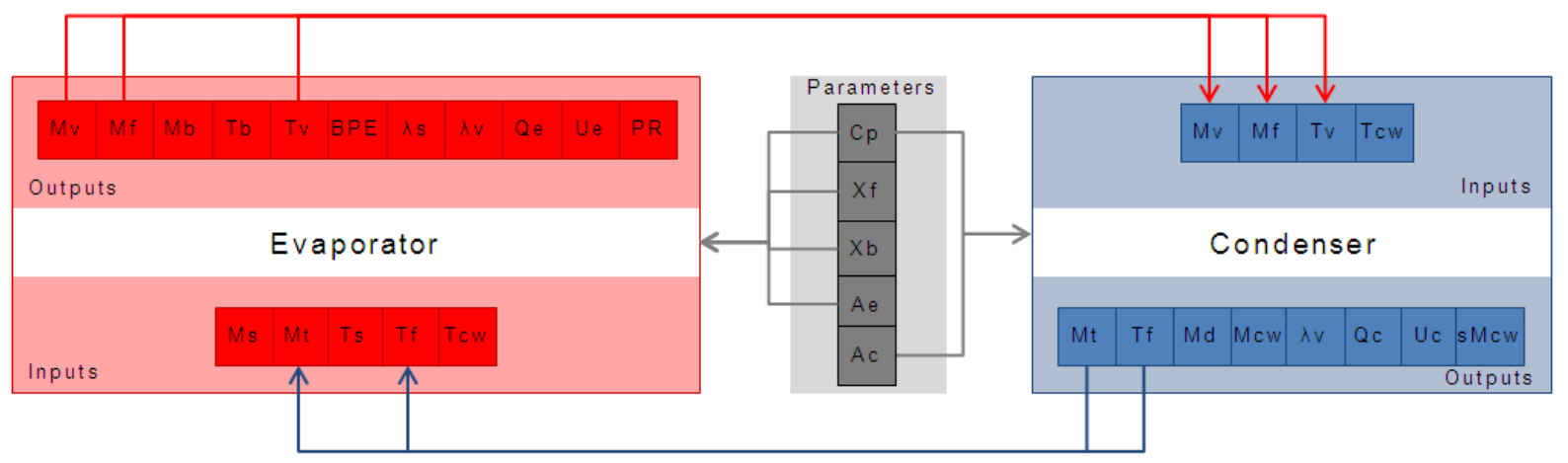

Figure 3 - Connections between the evaporator and condenser in the SEE system in TRNSYS.

\section{TRNSYS Model}

The TRNSYS model uses a graphical user interface (GUI), allowing drag-and-drop arrangements and editing of components icons. Also post-processing through the GUI and reporting is available (Clifford, 2008). In TRNSYS the component represents a physical process or feature in the system that can be added and developed as needed. A text based input file is read by the components, providing a solution of algebraic or differential equations as output. This model is based in FORTRAN programming language.

TRNSYS 16 was used for this work. Several components needed to make the simulation were available in this model, namely for CSP plants, but no components were available to simulate a complete SEE system. The components used were based on steady-state energy conservation (1st and 2nd laws) formulated in thermodynamic quantities (temperature, pressure, enthalpy) (Schwarzbözl, 2006).

The default TRNSYS solver was used for this simulation: the Successive Substitution (Solver 0); and the integration and convergence tolerances used were 0,001. This default solver is able to solve both deferential and non-linear equations (TRNSYS, 2007) and (Pina, 2010). In TRNSYS, components need to transform the current set of parameters and inputs into outputs. There are a few tools to help when complex solution techniques are needed: "SolveDiffEq" routine will analytically solve differential equations of a particular form. The TRNSYS kernel also solves differential equations numerically by a few different methods. A kernel routine called "LinearRegression" also exists that will carry out a curve fit on known data points. Beyond those tools, components need to incorporate their own solution techniques. This means that TRNSYS can solve systems of non-linear equations that arise between components. But if a non-linear equation needs to be solved inside one component, then the programmer will need to use external solver routines or make his own.

\subsection{Rankine cycle components (CSP) in TRNSYS}

The components to simulate CSP plants were available through the Solar Thermal Electrical Components (STEC) library (release 3.0 from 2006) for TRNSYS, freely offered by SolarPaces organization. This library contains the individual components needed to simulate different types of CSP plants with different configurations. The STEC library also came with example decks, where subsystems of CSP plants are described in detail and are available to be used for simulations. These already have the correct 
connections established between the individual components and the correct parameters. One of these example decks describes a simple Rankine cycle, which was used in this work.

This Rankine cycle is composed by several components, namely (Schwarzbözl, 2006): a boiler section (feedwater economizer and evaporator), turbine section (three turbines and two extraction lines), condenser module, deaerator, condenser preheater and a subcooler, condenser pump and feed water pump. The heat source for this Rankine cycle is simulated by a forcing function replicating a mass flow rate of steam. The temperature at which this heat source enters the Rankine cycle is predefined at 573,8 $\stackrel{\circ}{\circ}$.

\subsection{SEE components in TRNSYS}

To simulate a simple SEE system, two basic components are needed: an evaporator and a condenser. These are available in more than one TRNSYS component library though, none has been designed to assume its operation with saltwater. To solve this, a new evaporator and a condenser were built in TRNSYS using FORTRAN language in such a way that they could interact with other existing components.

It is possible to program the evaporator and condenser in TRNSYS in two ways: 1) as a single component ("combined-component"), or 2) as two individual components. The components were programmed separately in order to increase component modularity and reduce complexity of the code needed.

In this work, the equations describing the SEE system in steady-state are non-linear and they needed to be solved inside the components. This meant that TRNSYS could not solve this part of the problem as there are no internal subroutines that could be used for that inside the components (TRNSYS, 2007). To work this out, a simple loop was made to solve the non-linear equation system of each component, acting as a basic solver inside the condenser and the evaporator. The convergence tolerances used inside these "home-made" solvers, started in 0.001 , and decreased until 0.1 depending if a solution would be found or not before the end of the loop. The evaporator follows step 1) and 2) and 3.a) from the solution algorithm, and the condenser follows step 3.b).

By choosing to write two individual components, the TRNSYS solver calculates the equilibrium between the evaporator and the condenser, and no extra programming is necessary to reach a balance between the two components. Alternately, if just a single component was built for the SEE, another "home-made" solver would need to be made just to connect the results between the evaporator and condenser blocks, making probably the system slower during calculations.

The SEE system does not give feedback to the heat source. The deck created in TRNSYS to test the SEE system is presented in Figure 4, consisting of the evaporator, the condenser, and a printer and plotter components from TRNSYS to read the results. 


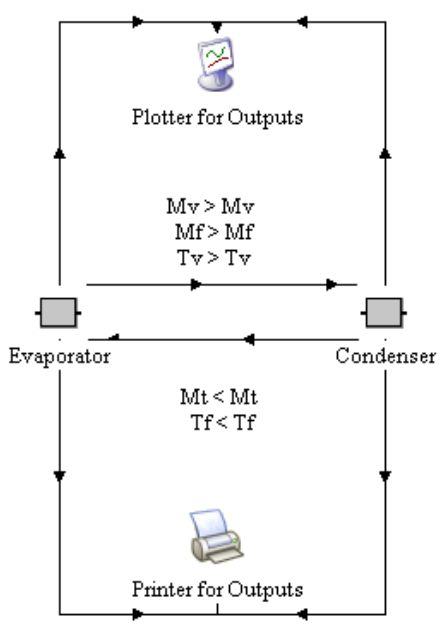

Figure 4 - TRNSYS deck to test a stand-alone SEE system

\subsection{Connection of the SEE with the Rankine Cycle}

In a Rankine cycle, the steam powering the desalination unit can be obtained by retrieving heat from several points in the steam turbines at different pressures and temperatures. Extracting steam at different places in the turbines will cause the power plant to have different electrical outputs (Mataix, 2000). If the steam is extracted before the exhaust of the LPT, a condenser will still be necessary (Blanco, 2011). In this work only the exhaust steam coming from the LPT was used as heat source for the SEE system.

In order to allow an easier connection between the Rankine cycle and the SEE system, a third new component was built to work as a "connector" to the SEE evaporator, acting as a subpart of the Evaporator. The existing condenser in the STEC Rankine cycle was replaced by this "connector", bridging the Low Pressure Steam Turbine (LPT), the SEE evaporator, and the condenser pump, as can be seen below in Figure 5. The main task of this "connector" is to predefine the condensation temperature in the system and then calculate the resulting pressure $(\mathrm{Pc})$.

Variables (Parameters, Inputs, Outputs) defined in the "connector":

- Parameters: Ts

- Inputs: Ms

- Outputs: Mcs, Tcs, Pc

The temperature at which the vapor will condense is predefined by the user in the "connector" before the simulation starts. The steam output from the LPT is assumed to be saturated with quality of one, and after condensation it is assumed to be $100 \%$ condensed (steam quality of zero). The LPT indicates to the connector its outlet steam flowrate.

A thermodynamic property subroutine of the STEC library called "Boil" is used inside the "connector" to calculate the pressure at which the vapor leaves the LPT. For a given temperature in ${ }^{\circ} \mathrm{C}$, this routine returns (amongst other) the pressure value in Bars for the saturation conditions (Schwarzbözl, 2006). This 
pressure information is provided to the LPT to act as its outlet steam pressure. Although the outlet pressure is a physical output of the LPT, it is defined as an input to reduce the complexity of the system.

As can be seen in Figure 5, the outputs of the "connector" will inform the SEE evaporator of the Ms and Ts that will be available to power it. No mass loss is assumed, and Ms equals Mcs. Ts is also equal to Tcs as steam input in the "connector" is considered saturated, and only latent heat is transferred. In Figure 5 the Rankine cycle is not shown in detail and is represented as a Macro in the TRNSYS deck, as it is not the main focus of this study. The connections between the components variables are indicated.

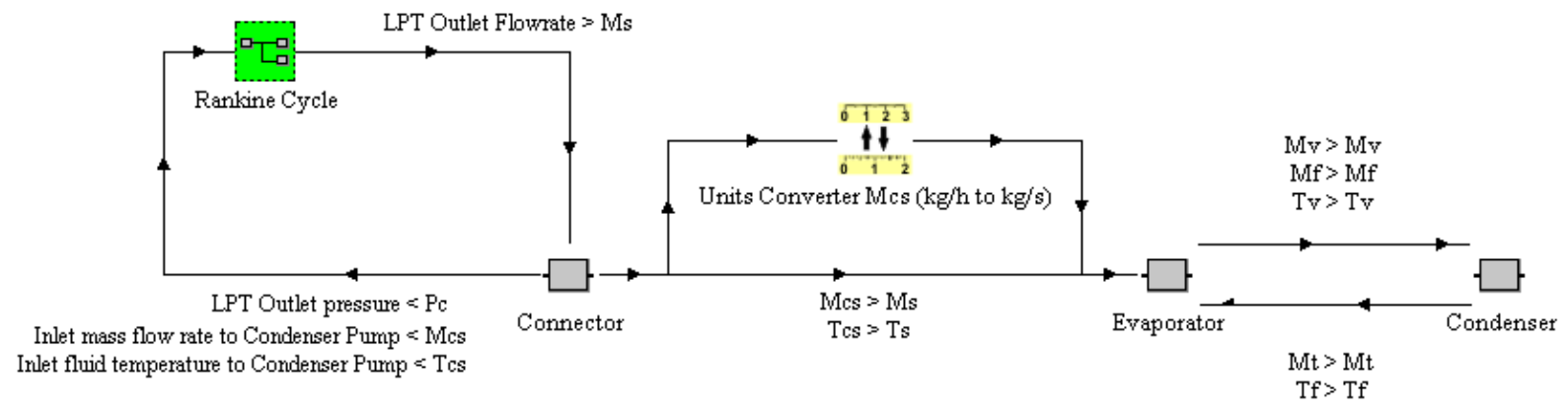

Figure 5 - TRNSYS deck with Rankine cycle + SEE system

The Mcs and Tcs outputs from the "connector" will also link with the inputs of the condenser pump in the Rankine cycle. As this study is an initial analysis to desalination systems in TRNSYS, there is no feedback from the SEE evaporator back to the Rankine cycle since the Ts is predefined in the "connector" and the steam from the LPT is assumed saturated.

\section{Scenarios}

Three simulation decks were used for this work. The first was to test the SEE system and validate its results with the reference data from the literature. The second, to simulate the performance of the Rankine cycle without the SEE system coupled. The third, to simulate the Rankine cycle coupled with the SEE system. Five scenarios were considered using decks two and three, as table 1 shows.

Table 1 - Scenarios description

\begin{tabular}{|c|c|c|c|c|c|}
\hline Scenario & Technologies used / TRNSYS deck & $\begin{array}{l}\text { Ts } \\
\left({ }^{\circ} \mathrm{C}\right)\end{array}$ & $\begin{array}{l}\mathrm{Tb} \\
\left({ }^{\circ} \mathrm{C}\right)\end{array}$ & $\begin{array}{c}\mathrm{Tf} \\
\left({ }^{\circ} \mathrm{C}\right)\end{array}$ & $\begin{array}{c}(\mathrm{Ae}+\mathrm{Ac}) \\
\left(\mathrm{m}^{2}\right)\end{array}$ \\
\hline 1. & $\begin{array}{l}\text { Rankine cycle with no SEE - Business as Usual (BAU) } \\
\text { (deck two) }\end{array}$ & - & 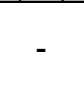 & - & - \\
\hline 2. & \multirow{4}{*}{$\begin{array}{l}\text { Rankine cycle with SEE } \\
\text { (deck three) }\end{array}$} & 50 & $\sim 36$ & $\sim 30$ & $\sim 800$ \\
\hline 3. & & 60 & $\sim 44$ & $\sim 36$ & $\sim 600$ \\
\hline 4. & & 70 & $\sim 54$ & $\sim 50$ & $\sim 600$ \\
\hline 5. & & 70 & $\sim 54$ & $\sim 43$ & $\sim 500$ \\
\hline
\end{tabular}

Through a thermodynamic characterization, the overall efficiencies for CSP+D were assessed. For this theoretical simulation, a 24 hour period was used with a time step of one hour. 


\section{Results and Discussion}

\subsection{SEE deck}

The deck created in TRNSYS to validate the SEE system consisted only of the evaporator and the condenser as can be seen in Figure 4. The inputs were predefined and did not vary over time so the equilibrium was reached from the first time step. Components "Type65d" and "Type25a" were part of the standard TRNSYS component library (TRNSYS, 2007) and were used to print and plot the outputs from the SEE system.

From (Ettouney, 2002), examples one, two and three from 'Chapter two - Single Effect Evaporation' were used as reference data and the results obtained from the simulation, only an error less than $0.5 \%$ presented when compared. The boundaries imposed on the system also gave the expected results, shutting down the SEE system when it was supposed to. The results obtained were also verified using the Visual basic computer package for thermal and membrane desalination processes (Ettouney, 2004), obtaining similar results in both programs.

\subsection{Rankine cycle deck (Scenario 1)}

Scenario 1 represents the BAU case, where no cogeneration is done and only electric production occurs. The simulation of the Rankine cycle as defined in the STEC deck, has an output of $103.9 \mathrm{MWh}$ during a simulation of 24 hours, reaching a peak power of 4,86 MWe and a minimum of 4,30 MWe (electrical generator efficiency was set to $90 \%$ ). The heat load available to the Rankine cycle varied through the 24 hours of the simulation as can be seen in Figure 6 . The mass flow rate of steam ranged from a maximum of $150000 \mathrm{~kg} / \mathrm{h}$ to a minimum of $129600 \mathrm{~kg} / \mathrm{h}$ and this is the reason for the oscillation in the power output of the turbines.

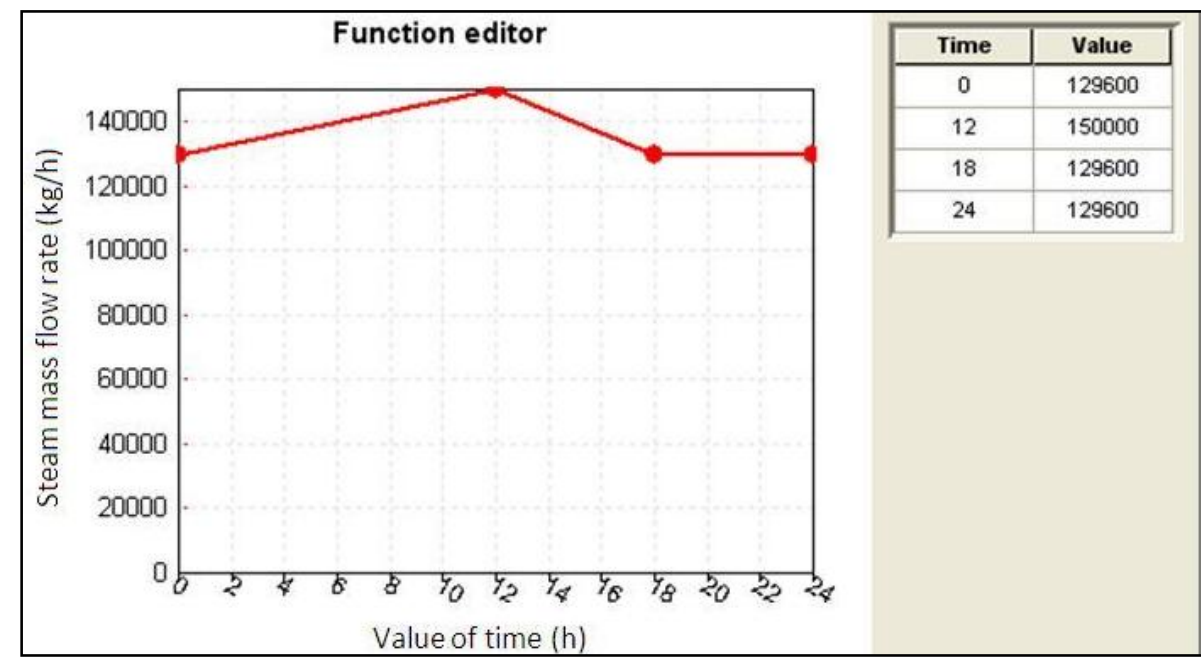

Figure 6 - Profile of the heat load made available to the Rankine cycle during the 24 hours of the simulation. 
The condenser in the Rankine cycle had the following variables predetermined before the start of the simulation: the exact temperatures for the Tcw, the cooling water outlet temperature (equivalent to Tf in the SEE) and the condensing temperature of the steam from the LPT (equivalent to Ts in the SEE). Being so, this component from STEC did not assume any values for heat transfer areas or coefficients.

\subsection{Rankine cycle + SEE system deck (Scenario 2, 3, 4 and 5)}

Scenario 2: In scenario two, the following parameters were predefined with these values:

SEE system:

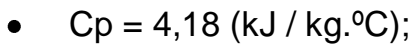

- $\quad X f=4,2$ (salt weight $\%=42000$ ppm);

- $\mathrm{Xb}=7$ (salt weight $\%=70000 \mathrm{ppm}$ );

- $A e=304\left(\mathrm{~m}^{2}\right)$;

- $A c=564\left(\mathrm{~m}^{2}\right)$;

- $\mathrm{Tcw}=20\left({ }^{\circ} \mathrm{C}\right)$;

\author{
Rankine cycle :
}

- $\mathrm{Ts}=50\left({ }^{\circ} \mathrm{C}\right)$

The heat transfer areas of the evaporator and condenser have been determined taking into account the mass of steam coming from the LPT and the Ts predefined temperature. Having this information, it was possible to define the Qe transferred to the SEE evaporator, using equation (7). By trial and error, reasonable values for Tb, Tv and Md were assumed ( $\sim 35^{\circ} \mathrm{C}, \sim 34^{\circ} \mathrm{C}$ and $\sim 4 \mathrm{~kg} / \mathrm{s}$, respectively) and an area could be calculated for the evaporator $\left(\approx 304 \mathrm{~m}^{2}\right)$ and condenser $\left(\approx 564 \mathrm{~m}^{2}\right)$ using equation $(2)$ and $(5)$ respectively. A minimum area allowed for the evaporator and condenser for a determined value of temperatures is already known to us. If the areas are smaller than this threshold value, even if a small positive temperature difference between TV and Tcw still exists and a massive amount of cooling water is circulated, it will not be able to condense all the steam in the other side of the heat transfer tubes using that heat transfer coefficient.

In scenario 2, when connecting the Rankine cycle to the SEE system by replacing the existing condenser in the STEC deck, the modified Rankine cycle has an output of 99,28 MWh during a simulation of 24 hours, reaching a peak power of $4,64 \mathrm{MW}$ and a minimum of $4,1 \mathrm{MW}$ (electrical generator efficiency was set to $90 \%)$. This represents less $4,4 \%$ of electricity produced ( $-4,62 \mathrm{MWh})$, compared with the operation of the Rankine cycle without the SEE system. On the other hand it is now possible to produce fresh water, obtaining $\approx 318 \mathrm{~m}^{3}$ in 24 hours.

The simple ratio between the $\mathrm{kWh}$ lost and the water production, gives a value of $25,16 \mathrm{kWh} / \mathrm{m}^{3}$ of water produced, which is an order of magnitude higher than the competing technologies specific energy consumption (SEC), namely LT-MED: $1.4-2.4 \mathrm{kWh} / \mathrm{m}^{3}$, TVC-MED: $1.2-2.2 \mathrm{kWh} / \mathrm{m}^{3}$; RO: $3.5-5.5 \mathrm{kWh} / \mathrm{m}^{3}$. It should be noticed that the SEC values include not only the loss in energy production in the turbines, but also the other main energy consumptions: the power required by the pumps, the desalination plant and cooling system. If an evaluation is made for the SEE system in this scenario which also includes these consumptions, the specific energy would be higher than $25,16 \mathrm{kWh} / \mathrm{m}^{3}$.

Changing only the parameters for the areas $(\mathrm{Ae}, \mathrm{Ac})$ and Ts from scenario 2 described above, the main outputs for the remaining scenarios 3, 4 and 5 are shown in Table 2. 
Table 2 - Scenarios main outputs

\begin{tabular}{|c|c|c|c|c|c|c|c|c|c|}
\hline Scenario & $\begin{array}{l}\text { Peak } \\
\text { Power } \\
\text { (MW) }\end{array}$ & $\begin{array}{l}\text { Min. } \\
\text { Power } \\
\text { (MW) }\end{array}$ & $\begin{array}{l}\text { Total } \\
\text { energy } \\
\text { produced } \\
\text { (MWh) } \\
\end{array}$ & $\begin{array}{l}\mathrm{H}_{2} \mathrm{O} \\
\text { produced } \\
\qquad\left(\mathrm{m}^{3}\right)\end{array}$ & $\begin{array}{c}\mathrm{kWh} / \mathrm{m}^{3} \\
\text { consumption }\end{array}$ & $\begin{array}{c}\mathrm{Tb} \\
\left({ }^{\circ} \mathrm{C}\right)\end{array}$ & $\begin{array}{c}\mathrm{Tf} \\
\left({ }^{\circ} \mathrm{C}\right)\end{array}$ & $\begin{array}{c}\mathrm{Mf} \\
\left(\mathrm{m}^{3}\right)\end{array}$ & $\begin{array}{c}\mathrm{Mt} \\
\left(\mathrm{m}^{3}\right)\end{array}$ \\
\hline 1. BAU & 4,86 & 4,30 & 103,9 & - & - & - & - & - & - \\
\hline $\begin{array}{l}\text { 2. Rankine+SEE } \\
\mathrm{Ts}=50^{\circ} \mathrm{C} \\
\mathrm{Ae}=304 \mathrm{~m}^{2} \\
\mathrm{Ac}=564 \mathrm{~m}^{2}\end{array}$ & 4,64 & 4,1 & 99,28 & 317,9 & 25,16 & $\begin{array}{l}37 / \\
35\end{array}$ & $\begin{array}{l}32 / \\
27\end{array}$ & 794 & $\begin{array}{r}1,75 \\
\times 10^{4}\end{array}$ \\
\hline $\begin{array}{l}\text { 3. Rankine+SEE } \\
\text { Ts }=60^{\circ} \mathrm{C} \\
\mathrm{Ae}=260 \mathrm{~m}^{2} \\
\mathrm{Ac}=359 \mathrm{~m}^{2}\end{array}$ & 4,45 & 3,95 & 95,9 & 318 & 27,84 & $\begin{array}{l}45 / \\
43\end{array}$ & $\begin{array}{l}39 / \\
33\end{array}$ & 797 & $\begin{array}{r}1,15 \\
\times 10^{4}\end{array}$ \\
\hline $\begin{array}{l}\text { 4. Rankine+SEE } \\
\mathrm{Ts}=70^{\circ} \mathrm{C} \\
\mathrm{Ae}=260 \mathrm{~m}^{2} \\
\mathrm{Ac}=359 \mathrm{~m}^{2}\end{array}$ & 4,33 & 3,81 & 92,37 & 328 & 35,15 & $\begin{array}{l}55 / \\
53\end{array}$ & $\begin{array}{l}52 / \\
47\end{array}$ & 821 & $\begin{array}{c}6,3 \\
x \\
10^{3}\end{array}$ \\
\hline $\begin{array}{l}\text { 5. Rankine+SEE } \\
\mathrm{Ts}=70^{\circ} \mathrm{C} \\
\mathrm{Ae}=251 \mathrm{~m}^{2} \\
\mathrm{Ac}=250 \mathrm{~m}^{2}\end{array}$ & 4,28 & 3,81 & 92,37 & 320 & 36.03 & $\begin{array}{l}55 / \\
53\end{array}$ & $\begin{array}{l}46 / \\
39\end{array}$ & 800 & $\begin{array}{c}7,9 x \\
10^{3}\end{array}$ \\
\hline
\end{tabular}

From these results, it is possible to conclude that the volumes of water required to run the system are very high, due mainly to the volume of cooling water needed. The total water distilled in scenario 2 represented only $\sim 4 \%$ of the total water pumped into the system. As the working temperature increases in the scenarios, this percentage rises up to $\sim 10 \%$, being still a very low value. On the other hand, the lower the operating temperatures in the SEE system, the lower the cost of $\mathrm{kWh}$ lost from the turbines per $\mathrm{m}^{3}$ of distilled water produced.

\section{Conclusions}

This paper describes the work done as a first approach to analyze the feasibility of CSP plants operating with desalination units. The first step for that was to model a basic evaporation system - the SEE - that could be used as a building block to understand more complex ones. This work presents a description of a SEE system and the mathematical equations describing it from the literature. Based on this information, an algorithm was created to model the SEE for steady-state operation, with as little inputs as possible for its two basic parts: the evaporator and condenser. These two blocks were programmed in FORTRAN, as modular components in a transient simulation program used as reference for the solar industry for many years: TRNSYS.

The performance of a SEE system powered by a Rankine cycle was analyzed in TRNSYS, using these two new components and the example deck from the STEC library (provided by SolarPaces) containing the Rankine cycle. Another reason for choosing a simple desalination system for this work was to reduce the complexity of the problem in hands and learn in an easier way how to integrate it in TRNSYS, especially because new components had to be built. 
This work confirms that the usage of the SEE for desalination is not technically competitive, as indicated by the literature. Though, this modeling and simulation experience will be important to evolve at a later stage into the simulation in TRNSYS of more complex thermal desalination technologies with better yields.

The output from the simulations show that: the lower the working temperatures are on the SEE system, the lower the number of $\mathrm{kWh}$ lost per $\mathrm{m}^{3}$ of water produced when connected to a power plant. This gain is offset by the increasing need for extra cooling water in the SEE as the working temperatures decrease.

\section{Acknowledgments}

This work was supported by SFRH/BD/44969/2008 PhD grant from Fundação para a Ciência e a Tecnologia (FCT), Portugal.

\section{References}

(Blanco, 2011) - J. Blanco, et al., 2011, 'Thermodynamic characterization of combined parabolic-trough solar power and desalination plants in Port Safaga (Egypt)', SolarPaces conference 2011, Granada.

(Pina, 2010) - H. Pina, Métodos Numéricos, 2010, Escolar Editora.

(Clifford, 2008) - Clifford, K., 2008, 'Software and Codes for Analysis of Concentrating Solar Power Technologies', Sandia National Laboratories, Albuquerque, New Mexico, USA.

(DLR, 2007) - 2007, AQUA-CSP Study Report, Concentrating Solar Power for Seawater Desalination - Final Report, German Aerospace Center, Institute of Technical Thermodynamics, Section Systems Analysis and Technology Assessment, Stuttgart, Germany.

(TRNSYS, 2007) - 2007, TRNSYS 16 Manual, 2007, Solar Energy Laboratory, University of Wisconsin-Madison. (Schwarzbözl, 2006) - P. Schwarzbözl, 2006, A TRNSYS Model Library for Solar Thermal Electric Components (STEC), Reference Manual, Release 3.0, SolarPaces, DLR, Germany.

(Ettouney, 2006) - H., Ettouney, 2006, 'Design of single-effect mechanical vapor compression', Desalination 190 (2006) 1-15.

(Ettouney, 2004) - H., Ettouney, 2004, 'Visual basic computer package for thermal and membrane desalination processes', Desalination, 165 (2004) 393-408.

(Ettouney, 2002) - H., Ettouney, et.al, 2002, Fundamentals of Salt Water Desalination, Elsevier.

(Mataix, 2000) - C. Mataix, 2000, Turbomáquinas Térmicas, Tercera Edicíon, Inversiones Editoriales. 